\title{
A study of Onychomycosis in Krishna district of Andhra Pradesh, India
}

\author{
Dusi Ratna Harika', Anaparthy Usharani ${ }^{2}$
}

${ }^{1}$ Asst.Professor, Department of Microbiology, Dr. Pinnamaneni Siddhartha Institute of Medical Sciences \& Research Foundation,
Chinnaoutapalli, Krishna district, India, ${ }^{2}$ Department of Microbiology, Rangaraya Medical College, Kakinada, India

Corresponding author: Prof. Anaparthy Usharani MD, E-mail: usharani.anaparthy@gmail.com

\begin{abstract}
Introduction: Onychomycosis is a chronic infection of nails caused by fungi such as dermatophytes, yeasts or nondermatophyte moulds. It is the most prevalent of all the nail ailments and affects 3-5\% of the population worldwide and represents $20-40 \%$ of onychopathies and about $30 \%$ of mycotic cutaneous infections. Aims: 1)To isolate and identify the etiological fungi and to assess the prevalence of onychomycosis. 2)To analyse the epidemiological and mycological features of onychomychosis. Methods: 109 nail samples were collected from 102 clinically suspected cases of onychomycosis and further analysed. Results: Of 102 cases, the commonest age group was 4l-50 years 38 (37.25\%); males were $63(61.76 \%)$ and females 39 (38.24\%); involvement of toe nails in 73 (71.57\%), finger nails $25(24.51 \%)$ and both 4 (3.92\%); 56 (54.90\%) belonged to low socio-economic status, middle 31 (30.39\%) and high 15 (14.71\%). Labourers were 14 (13.73\%), farmers and office personnel 10 (9.80\%). Of 109 samples, direct microscopy by KOH mount was positive in $82(75.23 \%)$ and fungal culture in $52(47.71 \%)$ of which 29 (26.61\%) yielded dermatophytes, NDM's $11(21.15 \%)$, Candida spp. 8 (15.38\%) and mixed growth 4 (7.68\%). Dermatophytes $25(48.08 \%)$ were the predominant group isolated from toe nails and Candida spp. $6(11.54 \%)$ from the finger nails respectively. Among the 56 isolates, dermatophytes were the predominant group 31 (55.36\%) followed by NDM's 15 (26.78\%) and Candida spp.10 (17.86\%). Conclusion: Onychomycosis is a frequent cause of nail infection. The mycological study and the identification of etiological agents of onychomycosis are needed to confirm the clinical diagnosis and for the choice of therapy.
\end{abstract}

Key words: Onychomychosis; Dermatophytes; Candida spp; Non dermatophyte molds

\section{INTRODUCTION}

Fungi are ubiquitous in nature. The term 'Onychomycosis' is derived from Greek word 'onyx', nail and 'mykes', fungus [1]. Onychomycosis comprises all fungal infections affecting the nail apparatus, i.e., nail matrix, nail plate, cuticle, mesenchymal tissue \& nail folds [2] and can be caused by dermatophytes, yeasts or non-dermatophyte moulds.

Onychomycosis has been referred to as the most prevalent of all the nail ailments and affects 3-5\% of the population worldwide [3] and represents 20$40 \%$ of onychopathies and about $30 \%$ of mycotic cutaneous infections [4]. Various workers have reported the incidence to vary from 0.5 to $5 \%$ in the general population in India [5]. The prevalence rate of onychomycosis is determined by age, predisposing factors, social class, occupation, climate, living environment and frequency of travel. Several factors have been implicated to the increase in disease such as reduced peripheral circulation, diabetes, nail trauma and difficulty to maintain proper nail hygiene [6]. Nail diseases can lead to impairment of hand function, difficulty in walking, and cosmetic disfigurement.

Dermatophytes are the most frequently implicated causative agents in onychomycosis approximately $90 \%$ in toe nail and $50 \%$ in finger nail infections [7]. The hyphae of the dermatophytes penetrate the stratum corneum of the skin and nails. The families

\footnotetext{
How to cite this article: Ratna Harika D, Usharani A. A study of onychomycosis in Krishna district of Andhra Pradesh, India. Our Dermatol Online. 2015;6(4):384-391. Submission: 01.04.2015; Acceptance: 20.06.2015

DOI: $10.7241 /$ ourd.20154.105
} 
that include many of the known keratinolytic fungi are the Arthrodermataceae and Onygenaceae in the phylum Ascomycota.Members of these families are homogenous with respect to appearance, physiology, taxonomy, antigenicity, basic growth requirements, infectivity, and the diseases they cause[8]. Being a pathogen and a colonizer, Candida albicans is also found in the environment, particularly on leaves, flowers, water, soil and infect more fingernails than toenails. Moulds are distributed worldwide. While they are commonly considered contaminants, they also cause infections in immunocompromised patients and in the elderly with damaged nail integrity [9]. The disease is more frequent among men than women \& it increases with age [10]. Toe nails are involved in the majority of cases. The ratio of finger nail to toe nail onychomycosis was found to be 1:4 [1].

Superficial fungal infections of the nail affect millions of individuals worldwide. In onychomycosis, infected nails serve as a chronic reservoir of infection which can give rise to repeated mycotic infections of the skin. It is of significance to suspect onychomycosis, perform mycological diagnosis and undertake treatment. This may help to prevent nail dystrophy and the spread of infection. Though onychomycosis is rarely life threatening, its chronicity, resulting cosmetic disfigurement and morbidity makes it an important public health problem.

\section{MATERIALS AND METHODS}

\section{Ethical Consideration}

The study was reviewed and approved by the Institutional Ethical Committee, Siddhartha Medical College and Government General Hospital, Vijayawada, Krishna district.

\section{Inclusion Criteria}

i) Clinically diagnosed cases of onychomycosis having destruction of nail plate, onycholysis, subungual hyperkeratosis, discoloration \& thickening of nail plate alone or in combination.ii) Patients of both sex and all ages. iii) Patients who were not on antifungal therapy.

\section{Exclusion Criteria}

i) Patients who had received treatment either with topical and/or systemic antifungal agents for present nail condition within the last one month. ii) Diagnosed cases of other dermatological diseases having nail changes eg. Psoriasis, Lichen Planus, Eczema,etc.

All cases with onychomycosis attending in Department of Dermatology, Government General Hospital, Vijayawada, Krishna dist., Andhra Pradesh from September 2011 to August 2012 were examined and selected based on history, clinical examination, inclusion and exclusion criteria. One hundred and nine samples from one hundred and two clinically suspected cases of onychomycosis (Fig. 1) were included in the present study. Nail clippings or subungual scrapings from all these cases were collected with a surgical blade after cleaning the affected area with $70 \%$ alcohol from the involved nail bed and from the undersurface of the nail.

The specimens were processed by direct microscopic examination using 20\% KOH (Fig. 2) and isolation by culture. Each of the samples was inoculated into two slopes of modified Sabouraud's dextrose agar (SDA, Himedia laboratories) slants, one with gentamycin and another with gentamycin and cycloheximide. Cultures were incubated at $25^{\circ} \mathrm{C}$ and $37^{\circ} \mathrm{C}$ and examined daily for first week and twice a week for 6 wks.

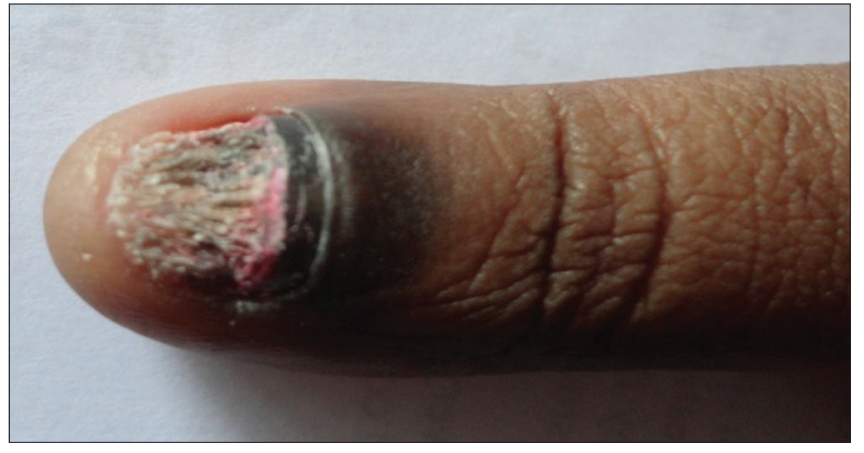

Figure 1: Onychomycosis affecting finger nail.

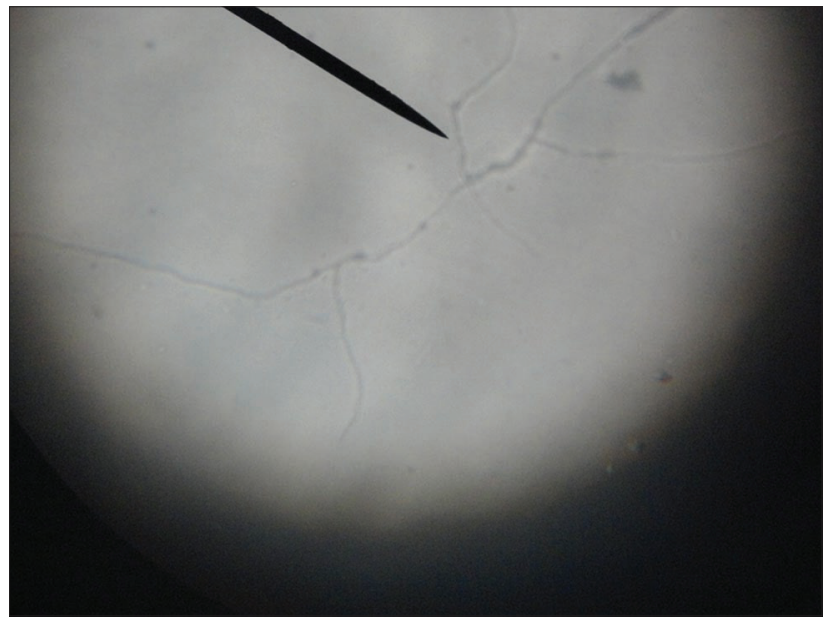

Figure 2: Direct - $\mathrm{KOH}$ wet mount, (40X). 
Each of the SDA tube was observed for texture, colony morphology, obverse and reverse pigmentation. If growth was present, a LPCB teased mount was prepared and examined under microscope. Gram stain was done and germ tube test performed when the growth was creamy. Yeast-like growths of the isolates were examined by Gram staining (Fig. 3), inoculated onto Hichrome agar (Fig. 4), cornmeal agar and SDA broth for presumptive identification of Candida species and their differentiation respectively. Slideculture was put up for mycelial isolates to study the undisturbed morphological details of the fungi. Biochemical reaction such as Urease test was done for differentiation of dermatophytes. Repeated cultures were done for confirmation of non-dermatophytic moulds (Figs 5 - 8).

\section{Identification}

Growth on SDA with actidione and antibiotics were identified as dermatophytes (Fig-9) as etiologic agents,

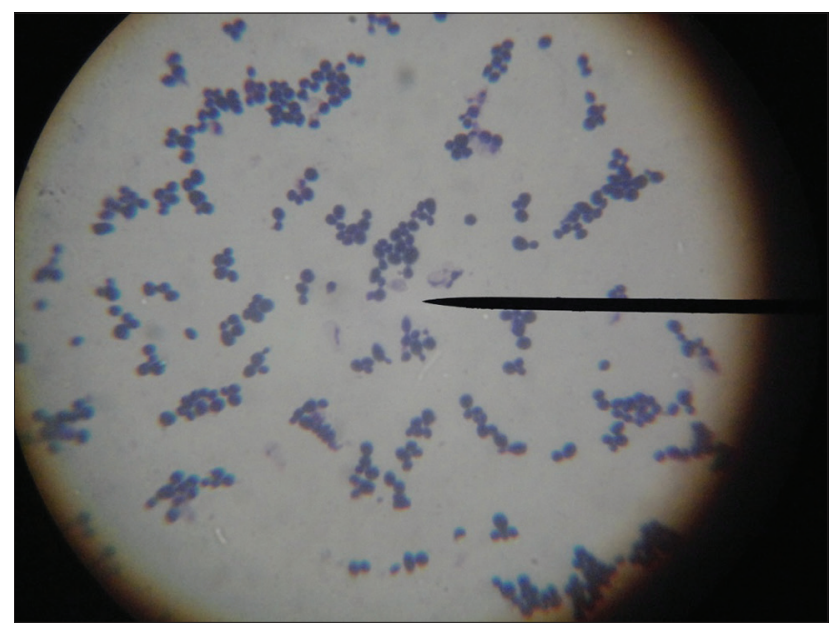

Figure 3: Gram positive budding yeast cells on Gram's staining.

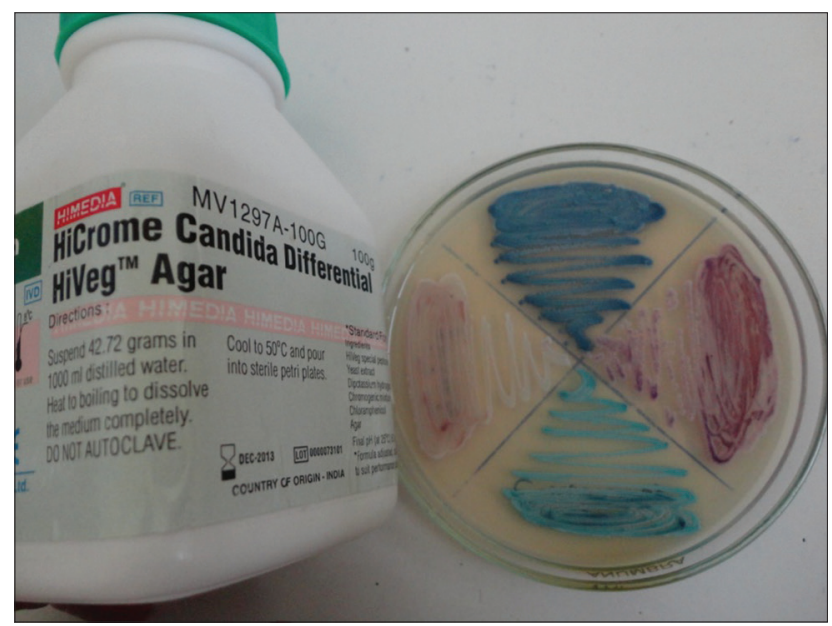

Figure 4: Growth of different Candida spp. on Hichrome agar. after observing microconidia and macroconidia under LPCB mount. The identification was confirmed by micromorphological aspects on slide culture and urease test which is positive with T.mentagrophytes and negative with T.rubrum. Candida species were identified by observation of budding yeast cells and pseudomycelium under light microscopy with $\mathrm{KOH}$, yeast-like growth on SDA medium and by gram positive budding yeast cells on Gram stained smear of the culture. Growth in the cyclo-heximide free medium indicates that the infective agent may be an NDM. The identification of non-dermatophytic fungi were confirmed by following micro and macroscopic evaluations of the primary cultures and slide culture. When the light microscopy of a nail specimen showed filaments with only a non-dermatophytic growth in culture, a second nail specimen was examined again by light microscopy and culture to confirm nondermatophytic mould infection.

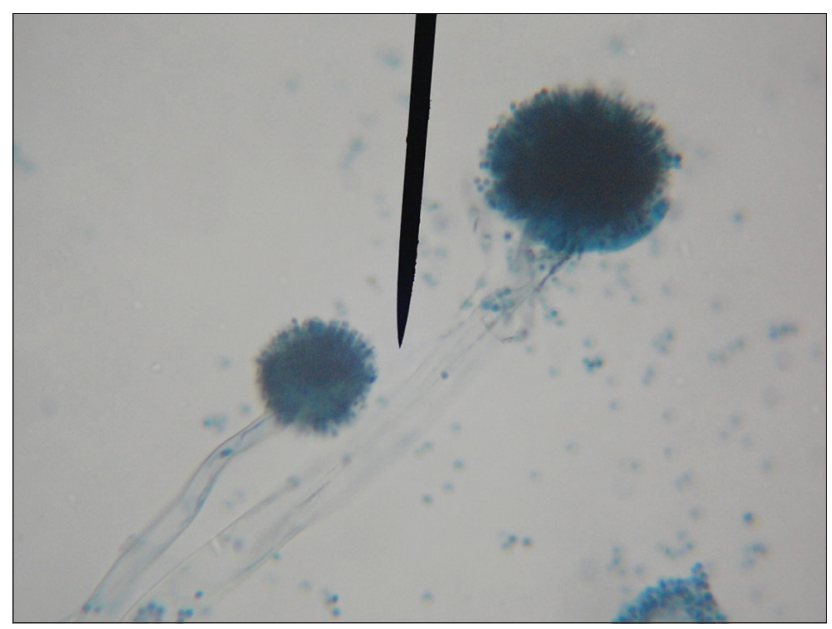

Figure 5: Aspergillus niger LPCB, (40X).

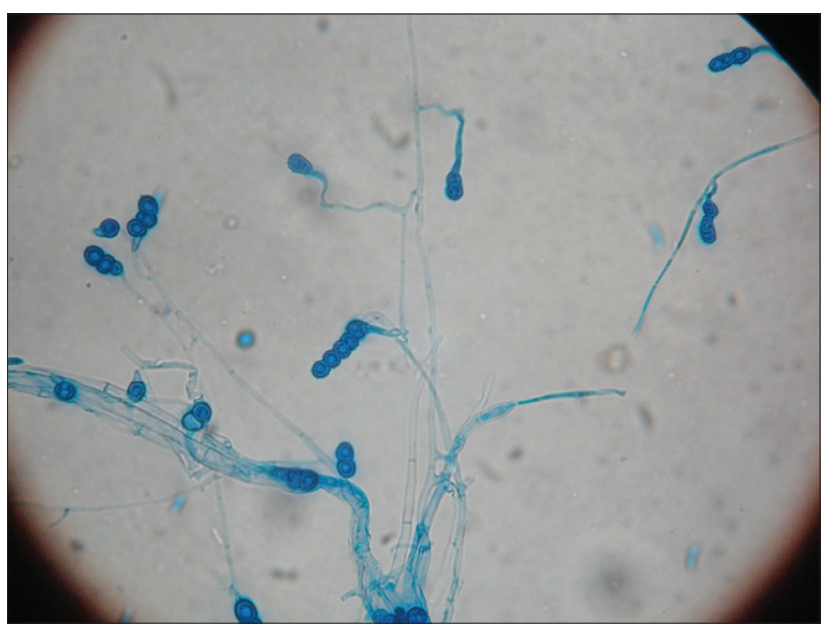

Figure 6: Scopulariopsis brevicaulis undisturbed morphology LPCB, (40X). 


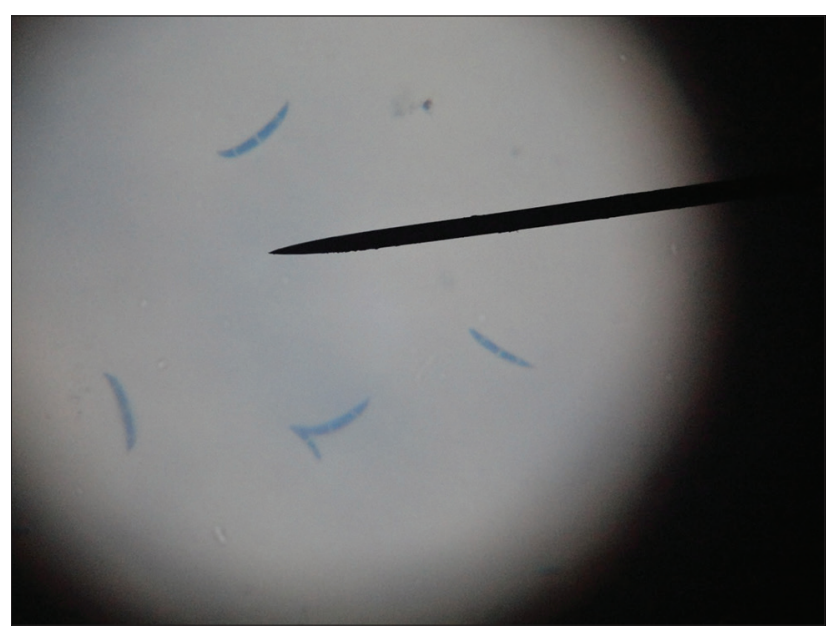

Figure 7: Fusarium spp. LPCB, (40X).

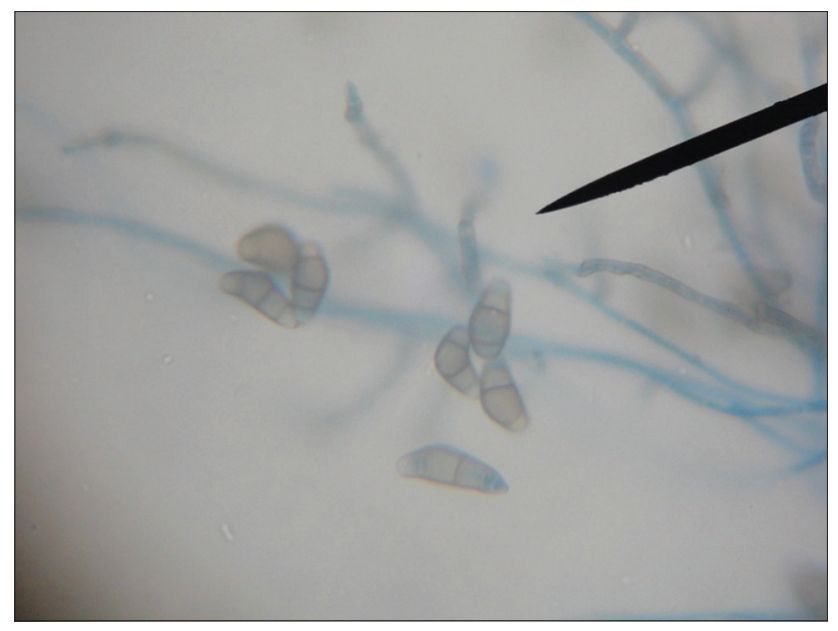

Figure 8: Curvularia spp. LPCB, (40X).

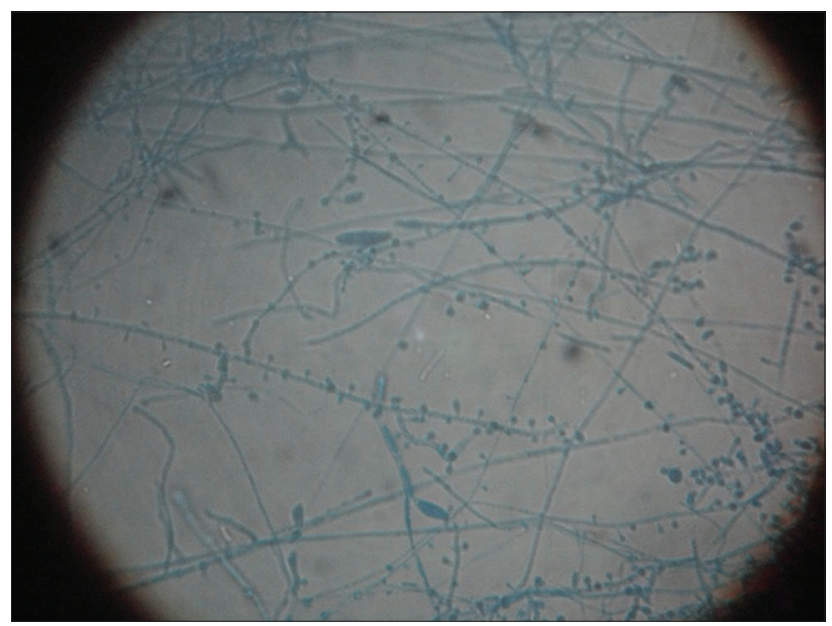

Figure 9: Trichophyton mentagrophytes LPCB, (40X).

\section{Ethics}

This study was performed on human subjects; thus, all patients were aware of the presence of the study and they were fully informed about the drug and its side-effects.

\section{RESULTS}

Of 102 cases (Table I), $41-50$ years 38 (37.25\%) were the commonest age group followed by 51 60 years $26(25.49 \%)$ with males $63(61.76 \%)$ and females 39 (38.24\%) and the ratio of male to female onychomycosis patients was approximately 1.6:1. It was more common in people of low-socio economic status $56(54.90 \%)$ followed by middle $31(30.39 \%)$ and high $15(14.71 \%)$.

Of the 102 cases, toe nails were the most frequent anatomic site involved in $73(71.57 \%)$ cases followed by finger nails in 25 (24.51\%) cases and both 4 (3.92\%) cases.

Of the 102 infected cases of onychomycosis, 109 samples (80toe nails,29 finger nails) were collected of which $38(37.26 \%)$ are associated with occupations due to increased physical activity followed by other occupations 37 (36.28\%) and occupations associated with wet work 27 (26.47\%) (Table II).

Distal and lateral subungual onychomycosis (DLSO) was the commonest clinical type 88 (80.73\%) and was followed by Paronychia 9 (8.26\%), Total dystrophic onychomycosis (TDO) 7 (6.42\%), Proximal subungual onychomycosis (PSO) $3(2.75 \%)$ and Superficial white onychomycosis(SWO) 2(1.83\%). Both DLSO \& Paronychia were most commonly seen in toe nails accounting for $61.47 \%$ and $5.50 \%$ respectively (Table III).

Direct microscopy by $\mathrm{KOH}$ mount was positive in $82(75.23 \%)$ cases and fungal culture in $52(47.71 \%)$ cases (Table IV). From 52 culture positive samples, 56 fungal isolates were obtained (Table V). Dermatophytes $25(48.08 \%)$ were the predominant group isolated from toe nails followed by non-dermatophyte moulds 8 (15.38\%) and Candida spp.2 (3.85\%). In the finger nails, Candida spp. 6 (11.54\%) were the predominant group isolated followed by dermatophytes 4 (7.7\%) and non-dermatophyte moulds 3(5.7\%). Mixed growth of two different fungi was observed in a single case of finger nail infection 1 (1.92\%) and 3 cases of toe nail infection of $1.92 \%$ each.

Among the 56 isolates (Table VI), dermatophytes were the predominant group 31 (55.36\%) with T. rubrum the most common species isolated 19(33.93\%) followed by T. mentagrophytes 11 (19.64\%) and M. nanum $1(1.79 \%)$. Non-dermatophyte filamentous fungi 
Table 1: Distribution of cases with onychomycosis in relation to age, gender, socio- economic status, nail involvement $(n=102)$

\begin{tabular}{lcc}
\hline Study group & No & Percentage \\
\hline Age in years & 1 & \\
$11-20$ & 12 & 0.98 \\
$21-30$ & 22 & 11.77 \\
$31-40$ & 38 & 21.57 \\
$41-50$ & 26 & 37.26 \\
$51-60$ & 3 & 25.49 \\
$61-70$ & & 2.94 \\
Gender & 63 & \\
Males & 39 & 61.76 \\
Females & & 38.24 \\
Socio economic & 56 & \\
Low & 31 & 54.90 \\
Middle & 15 & 30.39 \\
High & 73 & 14.71 \\
Toe nails & 25 & 71.57 \\
Finger nails & 4 & 24.51 \\
Both & & 3.92 \\
\hline
\end{tabular}

Table 2: Distribution of cases according to occupation ( $n=102)$

\begin{tabular}{lc}
\hline Category & No. of cases (\%) \\
\hline 1) Associated with increased physical activity & \\
Manual labourers & $14(13.73)$ \\
Farmers & $10(9.80)$ \\
Mechanics & $3(2.94)$ \\
Vehicle operators & $6(5.88)$ \\
Tailors & $5(4.90)$ \\
Total & $38(37.26)$ \\
2) Associated with wet work & \\
House wives & $7(6.86)$ \\
Domestic helpers & $7(6.86)$ \\
Washer men & $4(3.92)$ \\
Cooks & $2(1.96)$ \\
Hotel workers & $4(3.92)$ \\
Gardeners & $3(2.94)$ \\
Total & $27(26.47)$ \\
3) Others & \\
Office personnel & $10(9.80)$ \\
Businessmen & $7(6.86)$ \\
Students & $3(2.94)$ \\
Professionals & $9(8.82)$ \\
No specific occupation & $8(7.84)$ \\
Total & $37(36.28)$ \\
Total cases & 102 \\
\hline
\end{tabular}

Table 3: Clinical patterns of onychomycosis $(n=109)$

\begin{tabular}{lccc}
\hline Patterns & $\begin{array}{c}\text { Toe nails } \\
(\mathbf{n}=\mathbf{8 0})(\boldsymbol{)})\end{array}$ & $\begin{array}{c}\text { Finger nails } \\
(\mathbf{n = 2 9 )}(\%)\end{array}$ & $\begin{array}{c}\text { Total } \\
(\%)\end{array}$ \\
\hline DLSO & $67(61.47)$ & $21(19.27)$ & $88(80.73)$ \\
PSO & $1(0.92)$ & $2(1.83)$ & $3(2.75)$ \\
SWO & $2(1.83)$ & 0 & $2(1.83)$ \\
TDO & $4(3.67)$ & $3(2.75)$ & $7(6.42)$ \\
Paronychia & $6(5.50)$ & $3(2.75)$ & $9(8.26)$ \\
\hline
\end{tabular}

DLSO: Distal lateral subungual onychomycosis, PSO: Proximal subungual onychomycosis, SWO: Superficial white onychomycosis, TDO: Total dystrophic onychomycosis

$15(26.78 \%)$ constitute the second predominant group with Curvularia spp.3 (5.36\%), Aspergillus
Table 4: Microscopy and Culture positivity of the clinical samples $(\mathrm{n}=109)$

\begin{tabular}{lccc}
\hline \multirow{2}{*}{$\begin{array}{l}\text { Direct } \\
\text { examination }\end{array}$} & \multicolumn{2}{c}{ Fungal culture (\%) } & \multirow{2}{*}{$\begin{array}{c}\text { Total } \\
\text { non }\end{array}$} \\
\cline { 2 - 3 } & Positive & Negative & $(\%)$ \\
\hline KOH positive & $43(39.45)$ & $39(35.78)$ & $82(75.23)$ \\
KOH negative & $9(8.26)$ & $18(16.51)$ & $27(24.77)$ \\
Total & $52(47.71)$ & $57(52.29)$ & 109 \\
\hline
\end{tabular}

niger, Bipolaris spp. and Scopulariopsis brevicaulis of $2(3.57 \%)$ each and occasionally Aspergillus terreus, A.flavus, Alternaria spp., Fusarium spp., Scytalidium spp. and Scedosporium apiospermum of 1 (1.79\%) each were isolated. The other group of fungi isolated were the Candida spp. $10(17.86 \%)$ with C.albicans $6(10.71 \%)$,C.krusei $2(3.57 \%)$, C.tropicalis and C.glabrata of $1(1.79 \%)$ each.

\section{DISCUSSION}

Onychomycosis is a chronic infection of the nails; nowadays considered a serious problem for public health, in view of its high occurrence in the worldwide population. The prevalence is probably higher than currently thought, as the difficulty in clinicalmycological diagnosis, inappropriate collection of material for analysis as well as ineffective treatment make it hard to ascertain the true profile of such onychopathies.

This study was a prospective study conducted in the Department of Microbiology on one hundred and two cases of clinically diagnosed/suspected onychomycosis in an attempt to study the epidemiology of this disorder in the general population in and around Vijayawada, Andhra Pradesh.

In the present study of 102 cases (Table I), onychomycosis was common in the age group of 41-50 years 38 (37.26\%) followed by 51-60 years $26(25.49 \%)$. Although many reports indicate that the prevalence of onychomycosis increases with age, with the highest prevalence among the elderly more than 60 years old [7], there was a decreasing prevalence in patients over the age of 50 years in the present study. The increase in cases with age may be justified by the presence of antecedent diseases like DM, peripheral vascular disease, personal habits such as chronic smoking, trauma to the aged nails.

Of the 102 cases (Table I), there were more men $63(61.76 \%)$ than women 39 (38.24\%). Similar finding have been reported by some authors $[2,10]$ with a 
www.odermatol.com

Table 5: Onychomycosis due to different fungal groups: number of samples and isolates

\begin{tabular}{|c|c|c|c|c|c|c|c|c|c|}
\hline \multirow[t]{2}{*}{ Nails } & \multirow{2}{*}{$\begin{array}{l}\text { Dermatophytes } \\
\text { (DM) (\%) }\end{array}$} & \multirow{2}{*}{$\begin{array}{l}\text { Non-dermatophyte } \\
\text { molds (NDM) (\%) }\end{array}$} & \multirow{2}{*}{$\begin{array}{c}\text { Candida } \\
\text { spp (C) } \\
(\%)\end{array}$} & \multicolumn{4}{|c|}{ Mixed (\%) } & \multirow{2}{*}{$\begin{array}{c}\text { Total culture } \\
\text { positive } \\
\text { samples (\%) }\end{array}$} & \multirow{2}{*}{$\begin{array}{l}\text { Total } \\
\text { isola } \\
\text { tes }\end{array}$} \\
\hline & & & & $\mathrm{DM}+\mathrm{C}$ & $\mathrm{DM}+\mathrm{NDM}$ & $\mathrm{NDM}+\mathrm{NDM}$ & $\mathrm{NDM}+\mathrm{C}$ & & \\
\hline Finger nails & $4(7.7)$ & $3(5.7)$ & $6(11.54)$ & $\begin{array}{c}1 \text { (1.92) } \\
\text { (2 isolates) }\end{array}$ & 0 & 0 & 0 & $14(26.92)$ & 15 \\
\hline Toe nails & $25(48.08)$ & $8(15.38)$ & $2(3.85)$ & 0 & $\begin{array}{c}1(1.92) \\
(2 \text { isolates) }\end{array}$ & $\begin{array}{c}1 \text { (1.92) } \\
\text { (2 isolates) }\end{array}$ & $\begin{array}{c}1 \text { (1.92) } \\
\text { (2 isolates) }\end{array}$ & $38(73.08)$ & 41 \\
\hline Total & $29(55.77)$ & $11(21.15)$ & $8(15.38)$ & $1(1.92)$ & $1(1.92)$ & $1(1.92)$ & $1(1.92)$ & $52(100)$ & 56 \\
\hline
\end{tabular}

Table 6: Fungal isolates obtained from the clinical samples $(n=56)$

\begin{tabular}{lclc}
\hline Dermatophytes & $\begin{array}{c}\text { No.of } \\
\text { isolates (\%) }\end{array}$ & Candida spp. & $\begin{array}{c}\text { No.of } \\
\text { isolates (\%) }\end{array}$ \\
\hline $\begin{array}{l}\text { T.rubrum } \\
\text { T.mentagrophytes }\end{array}$ & $19(33.93)$ & C. albicans & $6(10.71)$ \\
M.nanum & $11(19.64)$ & C. krusei & $2(3.57)$ \\
& $1(1.79)$ & C. tropicalis & $1(1.79)$ \\
Total & C. glabrata & $1(1.79)$ \\
& Non- dermatophyte moulds (NDM) & $10(17.86)$ \\
Alternaria spp. & $1(1.79)$ & Curvularia spp. & $3(5.36)$ \\
A. niger & $2(3.57)$ & Fusarium spp. & $1(1.79)$ \\
A. terreus & $1(1.79)$ & S. brevicaulis & $2(3.57)$ \\
A. flavus & $1(1.79)$ & Scytalidium spp. & $1(1.79)$ \\
Bipolaris spp. & $2(3.57)$ & S. apiospermum & $1(1.79)$ \\
Total & & & $15(26.78)$ \\
Total isolates & & & 56 \\
\hline
\end{tabular}

prevalence of $75.4 \%$ and $65 \%$ respectively among men. However, few others $[4,11]$ have reported a high prevalence among women $(62.7 \%$ and $51.96 \%)$. The ratio of male to female onychomycosis in the present study was approximately 1.6:1 which coincides well with a study [12] of 1.63:1. Higher incidence in males may be because they are more exposed to outdoors with greater physical activity and are more prone to trauma of nails.

Onychomycosis was more common in people of low socioeconomic status $56(54.90 \%)$ in the present study (Table I) when compared to middle 31 (30.39\%) and high 15 (14.71\%), the reason being the higher prevalence of poor hygienic practices and overcrowding in this study group. Toe nails are about seven times more frequently involved than finger nails due to three times slower growth rate [13]. In the present study, toe nails were the most frequent anatomic site involved in $73(71.57 \%)$ cases and finger nails in $25(24.51 \%)$ cases and both nails concurrently in $4(3.92 \%)$ cases (Table I).

Manual labourers 14 (13.73\%) were the predominant group followed by farmers and office personnel $10(9.80 \%)$ each in the present study (Table II). Labourers on the other hand have increased perspiration, a greater risk of occupation- related trauma and exposure to soil saprophytes; while the use of occlusive footwear by office personnel might predispose them to onychomycosis. And in a similar study from Visakhapatnam [11], there was a higher prevalence in house wives $(33.33 \%$ ) as household wet work also appears to be an important predisposing factor.

In the present study, 109 samples (80toe nails, 29 finger nails) were collected from 102 cases as some of the cases had involvement of multiple sites and culture was done consequently. As per Table-III, the most frequent clinical presentation was DLSO 88 (80.73\%) followed by Paronychia in 9 (8.26\%)cases, a finding which is in consonance with earlier reports [2] from Himachal Pradesh. In contrast, DLSO (50\%) was the commonest presentation followed by PSO $(20.4 \%)$ in a study [10] from Aurangabad.

The two conventional methods used for identification of fungi were direct microscopy with $\mathrm{KOH}$ mount and fungal culture.Our study revealed a mycological positivity of $75.23 \%$ on direct microscopic examination(Table-IV) which was very sensitive for showing the presence of fungi. But it was lower than the results of various researchers $[10,14]$ who reported $81.8 \% \& 82.35 \%$ respectively, while this may be considered high when compared with the study [6] showing mycological positivity of $34 \%$. Culture positivity in the present study was $47.71 \%$, including $43(39.45 \%$ ) with positive direct examination and $9(8.26 \%)$ with negative direct examination as per Table IV which nearly correlated with the study [10] showing $48.8 \%$. In contrast to this, some authors $[12,15]$ have reported a comparatively high culture positivity rate of $62.7 \%$ and $60 \%$ respectively.

In the present study, as per Table-V has documented that dermatophytes 25 (48.08\%) were the predominant group isolated from toe nails and Candida spp. 6 (11.54\%) from the finger nails respectively, a similar finding in common with reports $[4,6]$ from Brazil and Delhi. The lesions due to dermatophytes commonly occur on feet as the warmth, moisture promote the contamination; sweating, cramped or tight fitting foot ware or rubber 
shoes prevent sweat evaporation and create the ideal environment for dermatophytoses. Local factors such as repeated damage of cuticle due to manicure, contact with substances containing sugars, wet work like washing, cooking, etc., and hyperhidrosis promote the infection with Candida [16].

As with dermatophyte infections, mould infections are much more common in the toe nails $8(15.38 \%)$ than in the finger nails $3(5.7 \%)$ in the present study (Table V). Non-dermatophyte moulds are filamentous fungi that are commonly found in nature as soil saprophytes and plant pathogens. Because these moulds are not keratinolytic, unlike dermatophytes, they only live on unkeratinized intercellular cement or must take advantage of previous keratin destruction by dermatophytes, trauma, or another nail disease i.e. these fungi act as secondary pathogen. Therefore, the isolates were confirmed after two repeated cultures of two different samples from the cases at different intervals. Reports from Tehran [17] and Turkey [18] show that mould onychomycosis is more frequent in toe nails than in finger nails and in the elderly. This situation can be prone due to more traumas to the nail with age and foot wear and also in labourers, and corresponds to very slow growth of finger and toe nail plates as well as to much higher incidence of impaired blood supply to the extremities.

In $7.68 \%$ of cultures, a mixture of dermatophytes or yeast-like or moulds were isolated. A single case of mixed infection of T.rubrum and C.albicans was observed in a finger nail. And the mixed isolates in the toe nails were geophilic M.nanum and Scedosporium apiospermum accounting for $1.79 \%$ of cultures. Fusarium and Scopulariopsis brevicaulis of $1.79 \%$ \& C.albicans and Curvularia spp. of $1.79 \%$ (Table V).Various authors from Turkey [18] and Indonesia [19] have reported mixed infections of dermatophytes and Candida spp. as 2\% and $2.21 \%$ of cultures respectively and 3 cases $(5.55 \%)$ of mixed infections of T.rubrum and Aspergillus niger have been reported from Jammu [20], all of which were low when compared with the present study. The most probable explanation for mixed etiology is that the diseased and dystrophic nails already damaged by dermatophytes are easily invaded by nondermatophytic moulds.

Among the 56 isolates in the present study as per Table VI, dermatophytes were the predominant isolates $31(55.36 \%)$ followed by non-dermatophyte moulds 15 (26.78\%) and Candida spp. 10 (17.86\%). A high incidence of onychomycosis due to dermatophytes was reported in studies from Delhi \& Sikkim [6,14] while Candida spp. were predominant in a study from Visakhapatnam [11] as this can be attributed to the fact that epidemiology of onychomycosis varies from one geographical region to other. The most common isolate obtained in the present study was T.rubrum 19 (33.93\%) and it was followed by T.mentagrophytes $11(19.64 \%)$, a finding in accordance with reports [10] from Aurangabad with isolation rates of T.rubrum (34.88\%) and T.mentagrophytes (25.58\%).

Non-dermatophytic filamentous fungi constitute the second predominant group with an isolation rate of $26.78 \%$ and the organisms in decreasing order of frequency are Curvularia 3 (5.36\%), Aspergillus niger, Bipolaris spp. and Scopulariopsis brevicaulis of $2(3.57 \%)$ each, A.terreus, A.flavus, Alternaria spp., Fusarium spp., Scytalidium spp. \& Scedosporium apiospermum of 1 (1.79\%) each (Table VI). Studies from different parts of India showed isolation rates of different moulds as $27.91 \%$ from Aurangabad [10], 35.14\% from Banglore [12], 35.71\% from Sikkim [14] all of which were higher than the present study and this variation may reflect geographic differences in mould distribution. Suggested predisposing factors for NDM involvement include increasing age, poor peripheral circulation, immunosuppression, peripheral neuropathy and trauma [7].

The other group of fungi isolated were the Candida spp. $10(17.86 \%)$ with C.albicans $6(10.71 \%)$ as the predominant species followed by C.krusei 2 (3.57\%), C. tropicalis\& C.glabrata $1(1.79 \%)$ one each in the present study (Table VI). It is believed that in tropical countries like India, hot humid climate may be a factor responsible for the causative role of yeasts.

The clinical diagnosis of onychomycosis should always be confirmed by direct microscopy and culture. Fungal culture of the subungual keratinous material provides final confirmation of the active cases of onychomycosis and enables to accurately pinpoint the causative organism. Compared to other studies, the low incidence of onychomycosis as seen in the present study may be because of low reporting, possibly due to less awareness and non hindrance of the problem to their occupation.

\section{CONCLUSION}

Onychomycosis is a frequent cause of nail infection. It is more prevalent in places where humidity and 
warmth are present. The mycological study and the identification of etiological agents of onychomycosis are needed to confirm the clinical diagnosis and for the choice of therapy. The etiological spectrum of onychomycosis is largely dependent on the flora in the immediate environment of the individual. It is influenced by geographic, climatic and occupational factors. It is desirable to determine the prevalence of etiologic agents of onychomycosis in any particular area in order to develop adequate control measures.

\section{Statement of Human and Animal Rights}

All procedures followed were in accordance with the ethical standards of the responsible committee on human experimentation (institutional and national) and with the Helsinki Declaration of 1975, as revised in 2008.

\section{Statement of Informed Consent}

Informed consent was obtained from all patients for being included in the study.

\section{REFERENCES}

1. Chander J. Textbook of Medical Mycology. (Chandigarh): Mehta publishers, p 122-142; 266-283; 508-516, 2009.

2. Gupta M, Sharma NL, Kanga AK, Mahajan VK, Tegta GR. Onychomycosis: Clinico- mycologic study of 130 patients from Himachal Pradesh, India. Indian J Dermatol Venereol Leprol. 2007;73:389-92.

3. Grover C, Khurana A. Onychomycosis: Newer insights in pathogenesis and diagnosis. Indian J Dermatol Venereol Leprol. 2012;78:263-70.

4. Lopes JO, Alves SH, Mari CRD, Oliveira LTO, Brum LM, Westphalen JB, et al. A ten-year survey of onychomycosis in the Central Region of the Rio Grande do Sul, Brazil. Rev Inst Med Trop S Paulo. 1999;41:147-9.

5. Kaur R, Kashyap B, Bhalla P. Onychomycosis- epidemiology, diagnosis and management. Indian J Med Microbiol. 2008;26:108-16.
6. Kaur R, Kashyap B, Bhalla P. A five-year survey of onychomycosis in New Delhi, India: Epidemiological and laboratory aspects. Indian J Dermatol. 2007;52:39-42.

7. Elewski BE. Onychomycosis: Pathogenesis, diagnosis and management. Clin Microbiol Rev. 1998;11:415-29.

8. Rippon JW. Medical mycology: the pathogenic fungi and the pathogenic actinomycetes. Philadelphia, Pa: The W.B. Saunders Co., p. 169-275, 1988.

9. Effendy I, Lecha M, Feuilhade de Chauvin M, Di Chiacchio N, Baran R. Epidemiology and clinical classification of onychomycosis. J European Acad Dermatol Venereol. 2005;19:8-12.

10. Veer P, Patwardhan NS, Damle AS. Study of onychomycosis: Prevailing fungi and pattern of infection. Indian J Med Microbiol. 2007;25:53-6.

11. Jesudanam TM, Rao GR, Lakshmi DJ, Kumari GR. Onycomycosis: A significant medical problem. Indian J Dermatol Venereol Leprol. 2002;68:326-9.

12. Grover S. Clinicomycological evaluation of onychomycosis at Bangalore and Jorhat. Indian J Dermatol Venerol Leprol. 2003;69:284-6.

13. Singal A, Khanna D. Onychomycosis: Diagnosis and management. Indian J Dermatol Venereol Leprol. 2011;77:659-72.

14. Adhikari L, Gupta AD, Pal R, Singh T. Clinico-etiologic correlates of onychomycosis in Sikkim. Indian J Pathol Microbiol. 2009;52:194-7.

15. Sujatha V, Grover S, Dash K, Singh G. A clinico - Mycological evaluation of onychomycosis. Indian J Dermatol Venereol Leprol. 2000;66:238-40.

16. Ramani R, Kumari GR, Shivananda PG. Onychomycosis in coastal Karnataka. Indian J.Med Microbiol. 1993;11:223-5.

17. Bassiri-Jahromi S, Khaksar AA. Nondermatophytic moulds as a causative agent of onychomycosis in Tehran. Indian J Dermatol. 2010;55:140-3.

18. Hilmioğlu-Polat S, Metin DY, Inci R, Dereli T, Kilinç I, Tümbay E. Non-dermatophytic molds as agents of onychomycosis in Izmir, Turkey - a prospective study. Mycopathologia. 2005;160:125-8.

19. Bramono K, Budimulja U. Epidemiology of onychomycosis in Indonesia: Data obtained from three individual studies. Jpn J Med Mycol. 2005;46:171-6.

20. Ahmad M, Gupta S, Gupte S. A clinico-mycological study of onychomycosis. Egyptian Dermatol Online J. 2010;6:1-9.

Copyright by Ratna Harika Dusi, et al. This is an open access article distributed under the terms of the Creative Commons Attribution License, which permits unrestricted use, distribution, and reproduction in any medium, provided the original author and source are credited.

Source of Support: Nil, Conflict of Interest: None declared. 